\title{
Pre-stack seismic density inversion in marine shale reservoirs in the southern Jiaoshiba area, Sichuan Basin, China
}

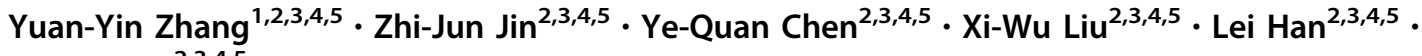 \\ Wu-Jun $\operatorname{Jin}^{2,3,4,5}$
}

Received: 16 October 2017 / Published online: 26 July 2018

(C) The Author(s) 2018

\begin{abstract}
For a typical marine shale reservoir in the Jiaoshiba area, Sichuan Basin of China, P-impedance is sensitive for identifying lithology but not suitable for indicating good shale reservoirs. In comparison, density is an important quantity, which is sensitive for identifying the organic-rich mud shale from non-organic-rich mud shale. Due to the poor data quality and incidence angle range, density cannot be easily inverted by directly solving the ill-posed pre-stack seismic inversion in this area. Meanwhile, the traditional density regularizations implemented by directly using the more robust P-impedance inversion tend to be inaccurate for recovering density for this shale reservoir. In this paper, we combine the P-impedance and the minus uranium to construct the pseudo-P-impedance (PIp) at well locations. The PIp is observed to be sensitive for identifying organic-rich mud shale and has a good correlation with density in this area. We employ the PIp-density relation into the pre-stack inversion framework to estimate density. Three types of regularization are tested on both numerical and field data: These are no regularization, traditional regularization and the proposed approach. It is observed that the proposed method is better for recovering the density of organic-rich mud shale in the Jiaoshiba area.
\end{abstract}

Keywords Density inversion · Pseudo-P-impedance $\cdot$ Pure P-wave data $\cdot$ Regularization

\section{Introduction}

As an important unconventional exploration target in China, the marine shale reservoir in the Jiaoshiba area, Sichuan basin is sealed by the upper mid-Silurian Xiaoheba siltstone and the lower Ordovician limestone (Chen et al.

\section{Edited by Jie Hao}

Yuan-Yin Zhang

yuanyinshou@163.com

1 Oil and Gas Survey, China Geological Survey, Beijing 100083, China

2 State Key Laboratory of Shale Oil and Gas Enrichment Mechanisms and Effective Development, Beijing 100083, China

3 State Energy Center for Shale Oil Research and Development, Beijing 100083, China

4 Sinopec Key Laboratory of Shale Oil/Gas Exploration and Production Technology, Beijing 100083, China

5 Petroleum Exploration and Production Research Institute, Sinopec, Beijing 100083, China 2015a, b; Jiang et al. 2017). Sequence stratigraphic analysis in this area suggests that this shale mainly consists of three intervals with different reservoir qualities. The lowest interval in particular is composed of black organic-rich mudstone and clay-rich siliceous mudstone with the highest total organic carbon (TOC) and gas contents (Chen et al. 2015a, b; Liang et al. 2016). For the identification of this interval, traditional acoustic properties, such as P-wave impedance (Ip) and S-wave impedance (Is), are incapable of assessing the shale brittleness, TOC and hydrocarbon content. In comparison, density is observed to be sensitive to the radioactive properties of organic matter and exhibits a significant correlation with reservoir quality. It is therefore desirable to invert for density from the seismic data in such reservoirs.

For the recovery of density based on seismic data, the full waveform approach (Jeong and Min 2012) often does not work well for field applications. Besides, the joint inversion using $\mathrm{P}-\mathrm{P}$ and $\mathrm{P}-\mathrm{S}$ data is also impossible due to the common insufficiency of multi-component data in most cases, even though density information is always present at small P-S reflection angles (Gray 2003). For the more 
conventional and widely available P-P data, amplitude variation with offset (AVO) is a function of four quantities: (1) the background $V_{\mathrm{P}} / V_{\mathrm{S}}$; (2) the $\mathrm{P}$-wave velocity contrast; (3) the S-wave velocity contrast; and (4) the density contrast across the interface. These parameters cannot be easily decoupled from one another in the AVO kernel. In addition, density inversion usually suffers from a stronger instability than the velocity or impedance inversion (Liu et al. 2013). Given the fact that the density contrast has a negligible influence on AVO at small incidence angles, large offset data are often required to provide a reliable estimation (Debski and Tarantola 1995). However, seismic reflection events at large offsets are often seriously distorted and need to be conditioned carefully due to normal moveout (NMO) stretching and tuning effects (Zhang et al. 2012). For the very rare situations when density contrast is a dominant contributor to the reflection coefficient, density may be estimated from near and far offsets (Behura et al. 2010). For the majority of cases, density inversion using field data is extremely ill-posed, as the data contain noise and the results will be unstable (Downton et al. 2001; Downton and Lines 2004; Alemie and Sacchi 2011).

In an effort to gain more stability and reduce nonuniqueness, a variety of regularizations are usually implemented during AVO inversion either explicitly or implicitly. Examples of these are the Bayesian approach of Buland and More (2003) which strongly depends on the choice of a prior probability distribution for the parameters of interest. There are many forms of the prior distribution to formulate the AVO inversion under a Bayesian framework: Gaussian (Buland and More 2003), Laplace (Theune et al. 2010), Cauchy (Downton 2005), Huber (Chen and Yin 2007) and Trivariate Cauchy (Alemie and Sacchi 2011). More integrally, the inverted parameters including P-, S-velocities or impedances and density are further regularized by additional conditions, i.e., the Gardner or $V_{\mathrm{p}}-V_{\mathrm{s}}$ equations (Russell and Hampson 2007; Zhang et al. 2015). Because the P-impedance or P-velocity inversion is comparably more stable and accurate than the density inversion even though the input data contain a certain degree of noise, so density is often enhanced by the P-parameter when they have an acceptable correlation (Rusell and Hampson 2007; Zhang et al. 2015).

However, both the data quality in terms of $\mathrm{S} / \mathrm{N}$ ratio and the incidence angle range in the Jiaoshiba area are inadequate for directly recovering accurate density results. Besides, the density is not correlated with P-impedance or $\mathrm{P}$-velocity in the shale interval. In this paper, we construct the pseudo-P-impedance (PIp) curve by combining the P-impedance (Ip) and the minus uranium $(-\mathrm{U}) \operatorname{logs}$ based on a proposed equation. The PIp is observed to be sensitive for identifying organic-rich mud shale in this place and can be inverted in a 3D space. Subsequently, the PIp that is inverted under the post-stack framework is employed to formulate the pre-stack density inversion of shale reservoirs. We also compared the inverted density results from both the numerical and the field data examples with those from the case of no regularization, a traditional approach.

\section{Geology background}

In the southeastern Sichuan Basin, central China, Lower Silurian marine shale reservoirs actively produce gas and are the target of an ongoing exploration effort by the Sinopec Company. The thick Longmaxi shale in the Jiaoshiba area was deposited in a passive continental margin environment during the early Silurian (Jiang et al. 2017). The Longmaxi shale is underlain by thick, shallow Ordovician marine limestone and capped by mid-Silurian Xiaoheba siltstone (Liang et al. 2016) (Fig. 1). The Jiaoshiba area experienced complex tectonic movements and currently demonstrates an obvious NNE trend fault zone in the Longmaxi Formation (Hao et al. 2008; Liang et al. 2012). Several well-described outcrops, cores and the $\log$ data in this area suggest that the lower Longmaxi shale is mainly characterized by black mudstones and common graptolite fossils (Member shale 3 in Fig. 1), whereas silty mudstones and turbidite siltstones are present on the top of this formation (Liang et al. 2016). Thick black shale deposits are favorably preserved during the anoxic environment caused by transgression. The considerably thick shale in the Longmaxi Formation (ranging from 90 to $250 \mathrm{~m}$ ) is extensively rich in organic matter and

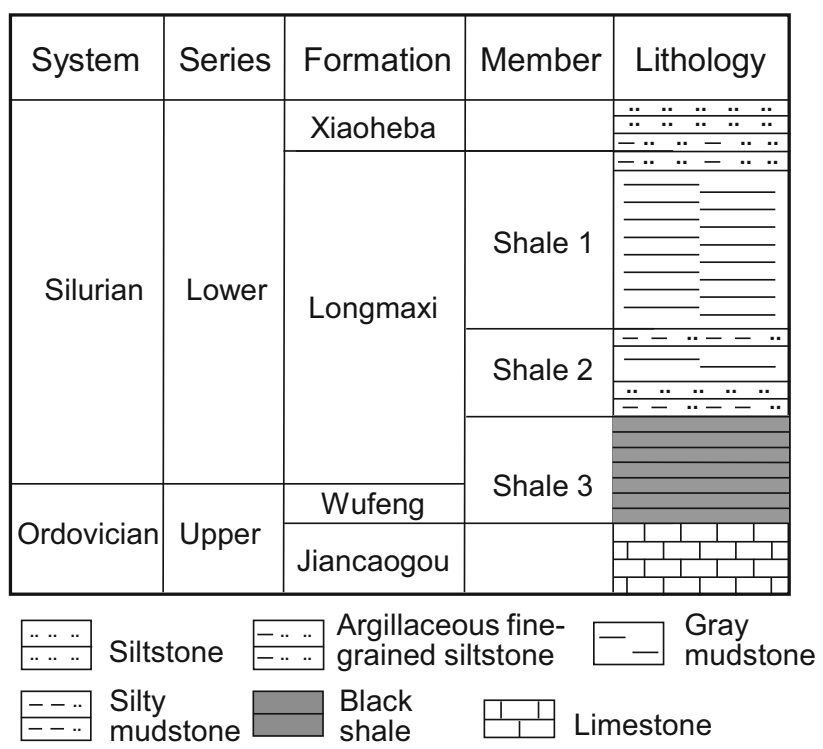

Fig. 1 Stratigraphic column for the study intervals in the Jiaoshiba area (modified from Jiang et al. 2017; Liang et al. 2016) 
contributes significantly to the prospectivity for shale gas exploration.

In particular, sequence stratigraphic studies indicate that the Longmaxi shale Formation is a third-order sequence including three members (Chen et al. 2015a, b). (1) The lower interval mainly contains black organic-rich mudstones and clay-rich siliceous mudstones with high TOC and brittle mineral contents, as well as the highest gas content (pink in Fig. 2). (2) The middle interval is primarily dominated by mixed siliceous mudstones and mixed silty mudstones with moderate TOC and gas contents (red in Fig. 2). (3) The upper interval is mainly composed of organic-lean and mixed gray mudstones with the lowest gas content (yellow in Fig. 2).

Logging identifications in this area reveal that the Longmaxi mud shale reservoir is generally characterized as low velocity, low density, high gamma ray and high uranium (Yan et al. 2014) (Fig. 2). Referring to the shale reservoir quality that is well characterized by TOC and gas content curves, the density, GR and uranium logs are capable of identifying the non-organic-rich mud shale from organic-rich mud shale in this place (Yan et al. 2014). In particular, the total porosity listed in Fig. 2 was calculated based on P-velocity logging, which is sensitive for identifying lithology, i.e., distinguishing the shale with low P-velocity value from upper siltstone and lower limestone, but not available for indicating good shale reservoirs (Figs. 2, 3). In comparison, from the top to the bottom of the Longmaxi shale formation, the increasing TOC and gas contents produce an obvious drop on the compensated density logging (Yan et al. 2014) (Figs. 2, 3). In fact, the

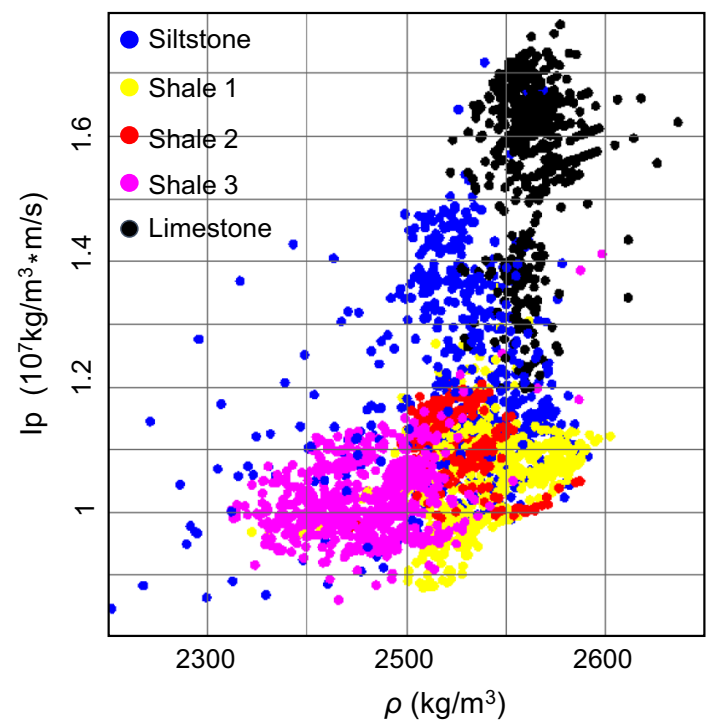

Fig. 3 Cross-plot between Ip and $\rho$ from Fig. 2. Different colors represent different intervals

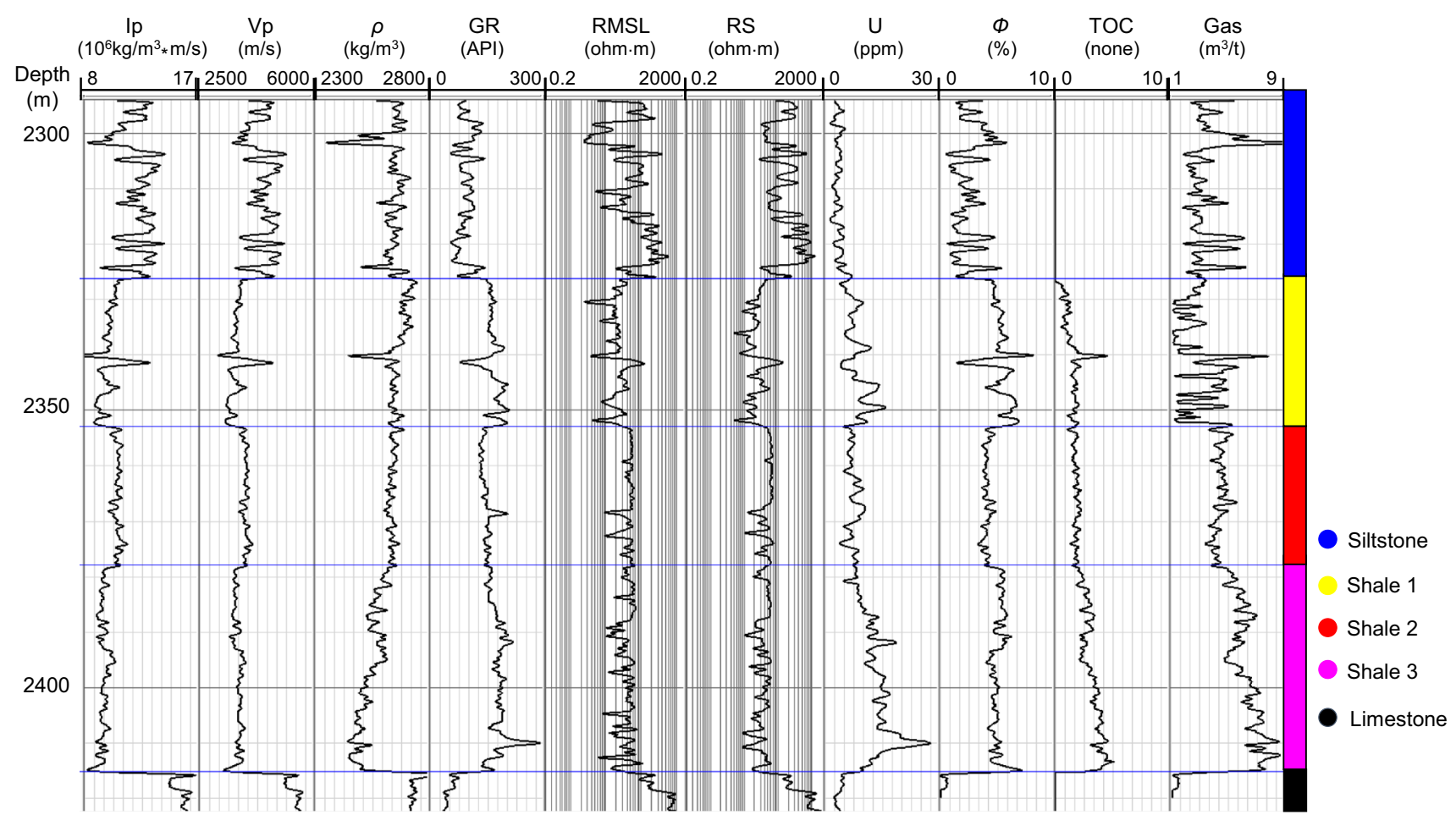

Fig. 2 Logs for a typical well from the Jiaoshiba area, Sichuan Basin. Ip P-impedance, $V_{\mathrm{p}} \mathrm{P}$-velocity, $\rho$ density, $G R$ natural gamma ray, $R M S L$ microspherical focused resistivity, $R S$ shallow lateral resistivity, $U$ uranium, $\Phi$ interpreted total porosity, TOC interpreted total organic carbon content, gas interpreted total gas content 
shale density in the Jiaoshiba area has a linear correlation coefficient of 0.75 when cross-plotted against brittleness, a correlation of 0.90 with the TOC, and a correlation of 0.80 with the gas content. Therefore, it is desirable to invert for density from the seismic data in such reservoirs. As the contributor besides $\mathrm{P}$ - and $\mathrm{S}$-velocities for the angle-dependent reflectivity series, the density parameter can be computed in theory under the current pre-stack seismic system.

Although the specific seismic acquisition system, i.e., wide azimuth angles, small intervals, high folds and long spread, as well as serious data processing, was applied to improve the seismic image precision for this shale reservoir (Chen et al. 2016), the seismic data quality is varying across the whole research area with an average $\mathrm{S} / \mathrm{N}$ ratio about 5. The largest incidence angle at the target shale reservoir is about $30^{\circ}$. These data may be beneficial for structural interpretation but are not appropriate to directly invert acceptable density results. Besides, the traditional effort that is regularized by utilizing the $\mathrm{Ip}-\rho$ relation is also incapable of enhancing density results.

\section{Pre-stack density inversion constrained by pseudo-P-impedance}

To reasonably improve density inversion precision under regularized pre-stack inversion framework, a comparably stable parameter-the pseudo-P-impedance instead of the P-impedance-was explored to formulate a better constraint in this paper. As shown in Fig. 4, this method includes three major approaches, including pseudo-Pimpedance (PIp) curve construction, pure $\mathrm{P}$-wave data computation and PIp inversion, as well as pre-stack inversion.

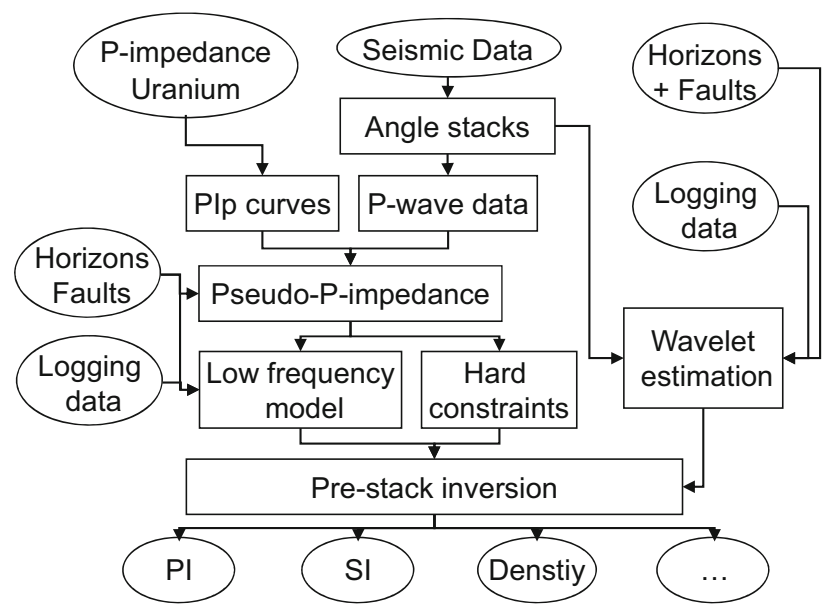

Fig. 4 Workflow of the pre-stack inversion constrained by using pseudo-P-impedance

\subsection{Pseudo-P-impedance (PIp) curve construction}

Normally, P- and S-slowness, density, GR and uranium logs are measureable surrounding a borehole and are relatively more accurate than other interpreted curves such as TOC, brittleness, total porosity. In particular, the uranium curve, that is showing energy-filtered borehole-side radioactivity, is observed to be capable of differentiating organic-rich shale from non-organic-rich shale (Fig. 2). Taking the example of well JY8 from the southern Jiaoshiba area (Fig. 5), the good shale (shale 3, pink color in Fig. 5a-i) accumulated with the most organic matter content often signifies a prosperous shale gas content and produces an obvious response in the $\mathrm{U} \log$ (Fig. 5b). By contrast, the P-impedances of the three sets of shale are quite similar (Fig. 5a), as well as those of the upper argillaceous sandstone-as demonstrated in the superimposed histogram distribution in Fig. 5h. Although the P-impedance (Ip) attribute has the highest precision during the AVO inversion and can be computed in a post-stack inversion framework, it appears to be lacking the ability to identify a good shale reservoir.

In comparison, the pseudo-log recomposition technique based on multiple well logs is often proposed for loggingconstrained inversion for the purpose of reservoir prediction (Yin et al. 2014a). Yin et al. (2014b) rebuilt the pseudo-acoustic $\log$ to quantitatively predict the highquality shale reservoirs in the Jiaoshiba area, on the basis of the interpreted TOC and original acoustic logs. In this paper, we construct the pseudo-P-impedance (PIp) curve by combining the P-impedance (Ip) and measurable minus uranium $(-\mathrm{U})$ curves, under the uniformization scale:

$\operatorname{norm}(\mathrm{PIp})=a[\operatorname{norm}(\mathrm{Ip})]+b[\operatorname{norm}(-\mathrm{U})]$

where $\operatorname{norm}(\mathbf{x})$ represents the function of normalization applied on $\mathbf{x}$. $a$ and $b$ are the weight parameters, and $a+b=1$. In detail, the Ip and minus U curves (Fig. 5a, b) are, respectively, normalized to $[0,1]$ (Fig. $5 c$, d) at first and are subsequently combined to form norm(PIp) (Fig. 5e) by using the tested weight parameters ( $a=0.6$; $b=0.4$ ) based on Eq. (1). The two weight parameters are selected on the principle that: (1) The constructed PIp should be competent for distinguishing good shale reservoirs, and (2) the norm(PIp) and norm(Ip) should have similar seismograms in the seismic band. The combined data are further extended to the same range with Ip by utilizing the reversed function of normalization (Fig. 5f).

As one of the most direct indicators for organic matter and hydrocarbon content in the shale layer, the uranium logging essentially indicates the accumulated uranium element content, which is associated with organic content. PIp is by nature a combination of the shale radioactivity 


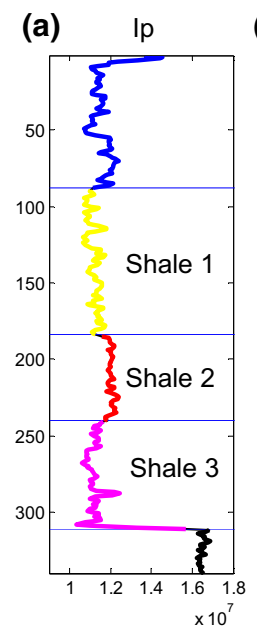

$\mathrm{kg} / \mathrm{m}^{3} * \mathrm{~m} / \mathrm{s}$ (b) $\quad u$

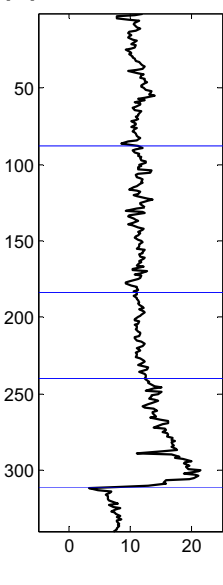

$\%$ (c) Normalized Ip

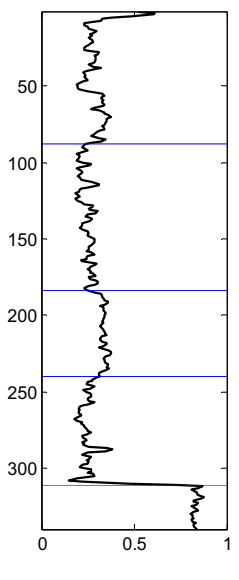

none (d) Normalized -U (e) Normalized PIp

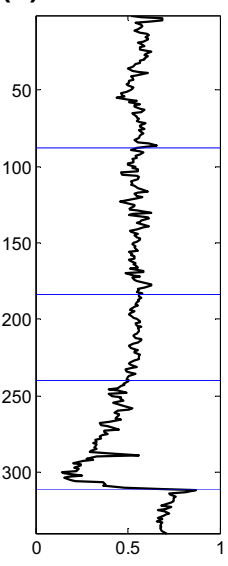

none (f) $\quad \mathrm{Plp}$

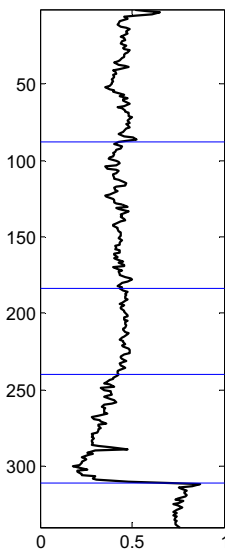

none (g) Density

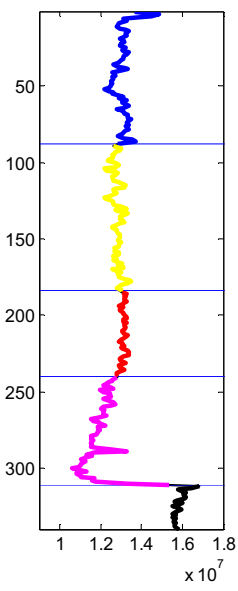

$\mathrm{kg} / \mathrm{m}^{3} * \mathrm{~m} / \mathrm{s}$

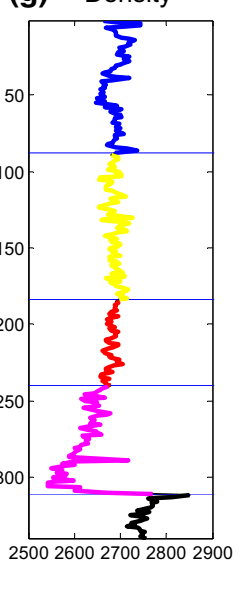

$\mathrm{kg} / \mathrm{m}^{3}$

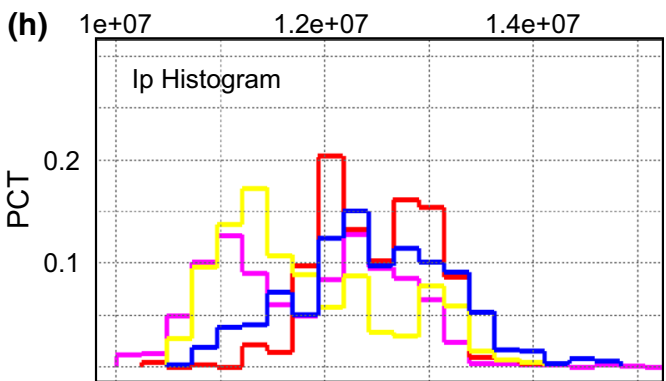

Fig. 5 Comparison of a P-impedance (Ip), b uranium index U; c normalized Ip; d normalized minus U; e normalized pseudo-Pimpedance (PIp); f constructed PIp; and $\mathbf{g}$ density $(\rho)$ curves in well JY8 from the Jiaoshiba area. The Ip distributions of sandstone and

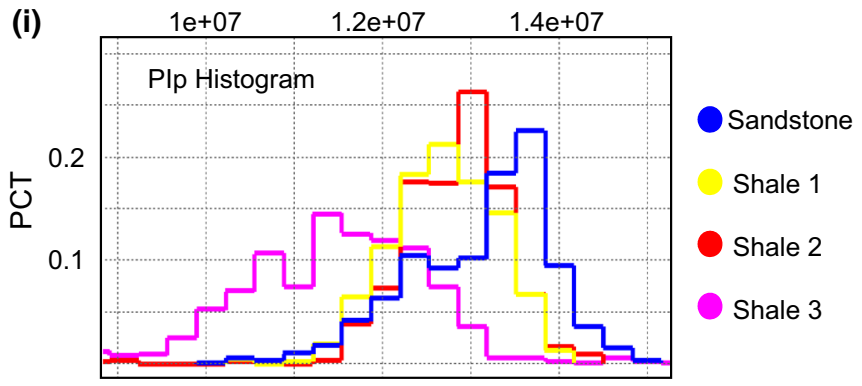

three sections of shale are comingled in $\mathbf{h}$, while in $\mathbf{i}$ the PIp histogram illustrates that the good shale (in pink) can be differentiated from the other lithologies. The vertical scales of panel a to $\mathbf{g}$ represent sample points (a)

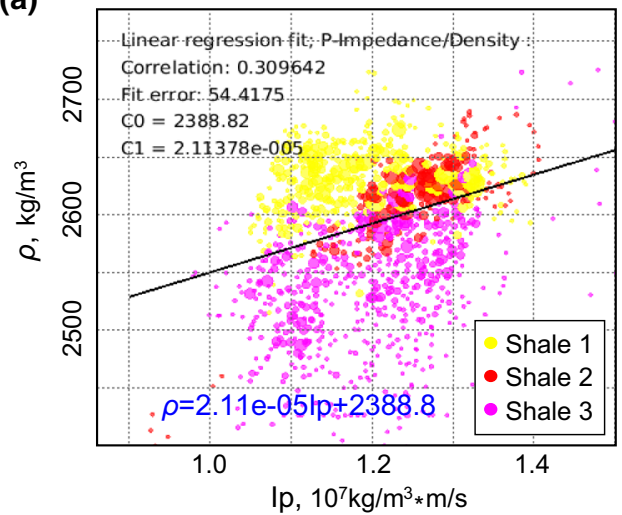

(b)

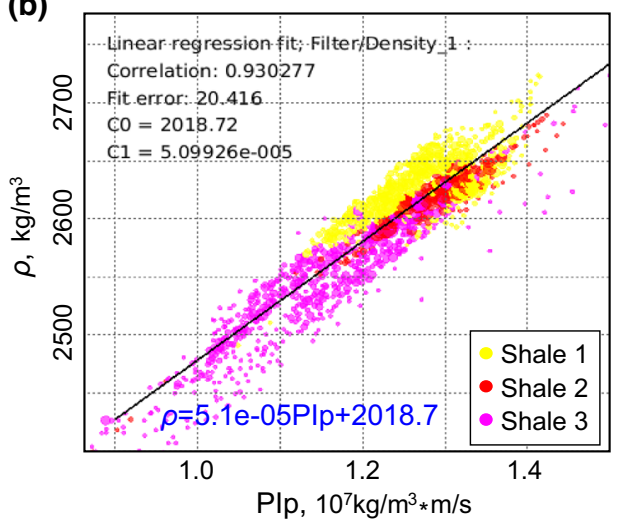

Fig. 6 Comparison between the cross-plots of $\rho$ and Ip (a) and that of $\rho$ and PIp (b) for the shale layer in Fig. 5. The $\rho$ and PIp cross-plot demonstrates a significantly higher correlation than that of the $\rho$ and Ip cross-plot

and acoustic properties. As shown in Fig. $5 \mathrm{f}$ and $5 \mathrm{a}$, this contrast between PIp with Ip demonstrates that the PIp is a much better identifier of good reservoir intervals. We observe a qualitative similarity between the density and the PIp (Fig. 5f, g), clearly better than the comparison between density and Ip (Fig. 5g, a). Quantitatively, the cross-plot analysis further indicates an acceptable linear regression between density and the PIp with a correlation coefficient of 0.93 at the shale layer (Fig. 6b), while the Ip only exhibits low correlation (coefficient of 0.31 ) with the density (Fig. 6a). 

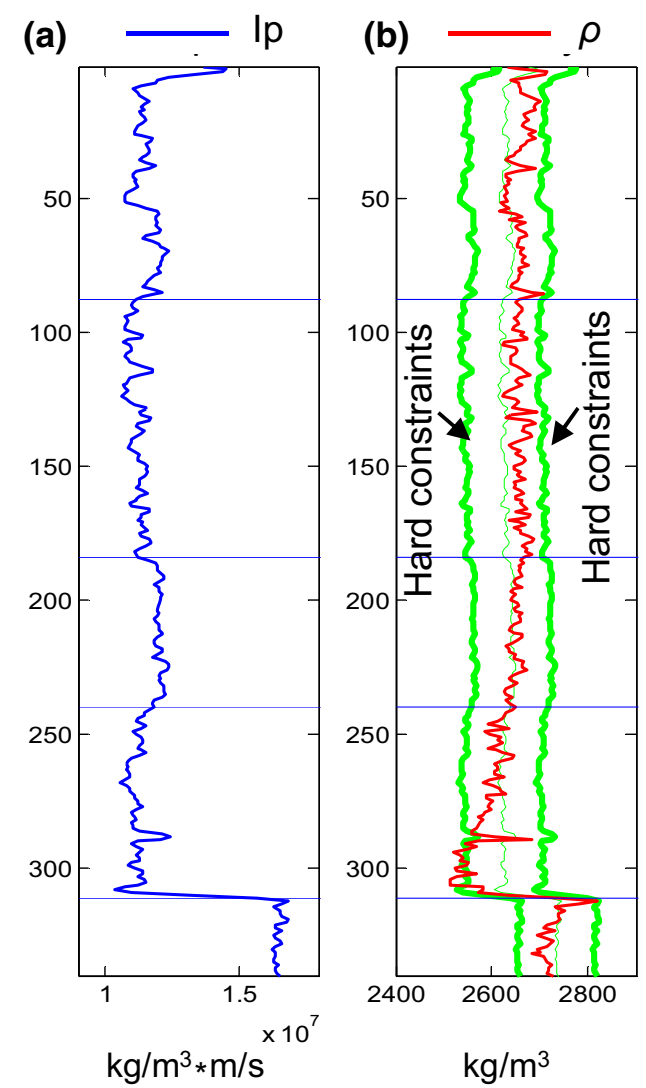

Fig. 7 Comparison of a P-impedance (Ip), c pseudo-P-impedance (PIp) and their corresponding constraints $\mathbf{b}$ and $\mathbf{d}$ for density (red line). Bold green lines mark the hard constraints built from the Ip and

Normally, P-impedance has the highest robustness among all the inverted parameters during AVO inversion, and the stability of density inversion is often enhanced by implementing suitable regularizations-such as the Ip- $\rho$ relation (i.e., the Gardner equation) mentioned above (Zhang et al. 2015), especially when they have a welldefined relationship (Zhang et al. 2015). A regional or statistical equation between P-impedance and density is definitely more preferable. Nevertheless, for this particular shale reservoir, the hard constraints directly constructed from P-impedance (Fig. 7a) are inappropriate to guide density inversion, especially in good quality reservoir layers (Fig. 7b). This is because the radioactivity and acoustic properties of good shale reservoirs are often not correlated with each other, and as described previously that PIp is a better parameter to use. Benefiting from the good correlation between PIp and density (Fig. 7b), a reasonable initial value (the fine green line in Fig. 7d) and hard constraints (the bold green lines in Fig. 7d) for density inversion can be built from PIp.

To illustrate the effectiveness of PIp inversion comparing with Ip inversion in the shale reservoir, we compared their reflectivity series (Fig. 8c, d) and synthetic
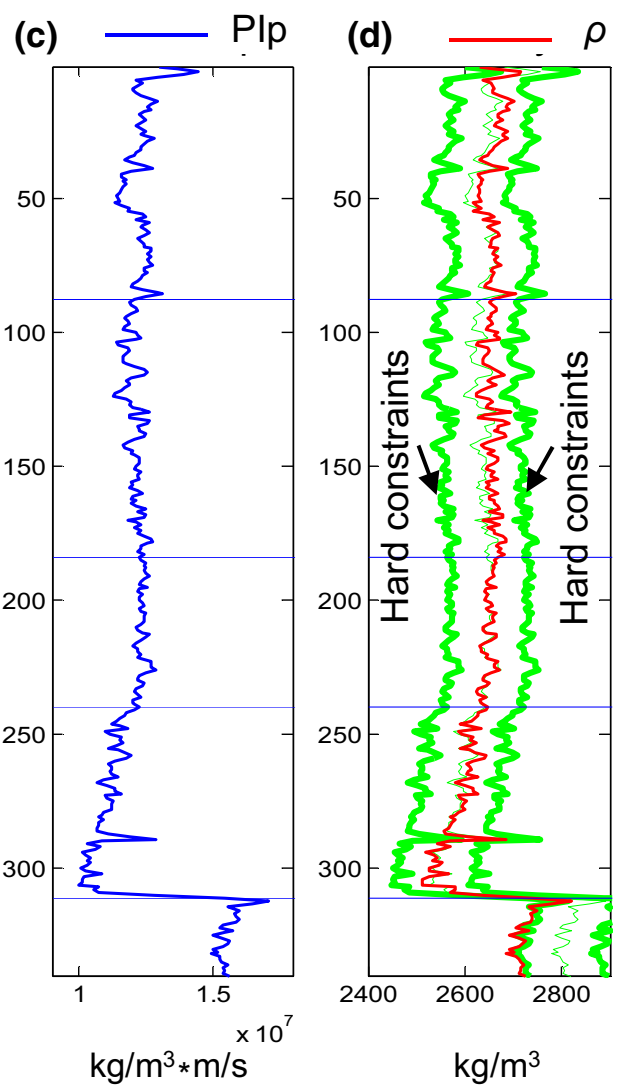

the PIp. Fine green lines indicate the possible initial values for the density inversion. In contrast, the PIp brings a better regularization for the density inversion

seismograms (Fig. 8e, f) at the seismic band (using the Ricker wavelet for modeling, dominant frequency $=25 \mathrm{~Hz}$ ). The Ip and constructed PIp curves, as well as their reflectivity series, might trend differently, but their seismograms in the finite seismic band show a substantial similarity, which suggests that the PIp attribute can be inverted by using the post-stack impedance inversion with appropriate initial models and constraints.

\subsection{Pure P-wave data computation and Plp inversion}

To attack the contamination of AVO effects on post-stack data in this area, we compute the P-wave data based on Eq. (2) (Gidlow et al. 1992; Sun 1999; Zhang et al. 2011, 2013):

$$
\begin{aligned}
R_{\mathrm{pp}}(\theta)= & \left(1+\tan ^{2} \theta\right) R_{\mathrm{p}}-8 \frac{V_{\mathrm{s}}^{2}}{V_{\mathrm{p}}^{2}} R_{\mathrm{s}} \sin ^{2} \theta \\
& -\left(\frac{1}{2} \tan ^{2} \theta-2 \frac{V_{\mathrm{s}}^{2}}{V_{\mathrm{p}}^{2}} \sin ^{2} \theta\right) \frac{\Delta \rho}{\rho}
\end{aligned}
$$

where $R_{\mathrm{p}}$ and $R_{\mathrm{s}}$ are theoretical zero-offset $\mathrm{P}$-wave reflectivity and $\mathrm{S}$-wave reflectivity, respectively, 


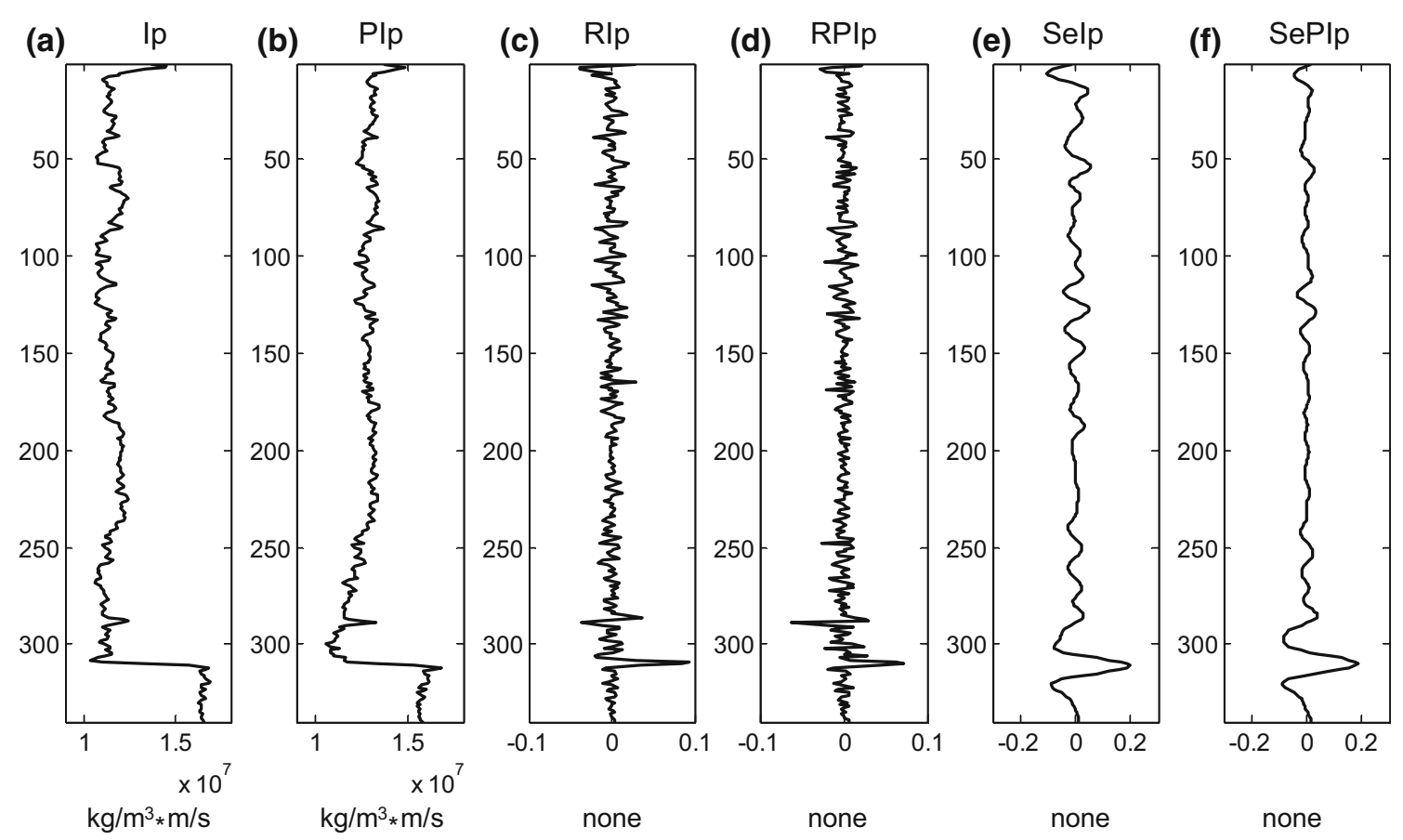

Fig. 8 Comparison of a the P-impedance (Ip) and $\mathbf{b}$ pseudo-P-impedance (PIp) from Fig. 6, as well as their corresponding zero incidence reflectivity series (c and $\mathbf{d}$ ) and synthetic seismograms (e and $\mathbf{f}$ ) at the finite seismic band

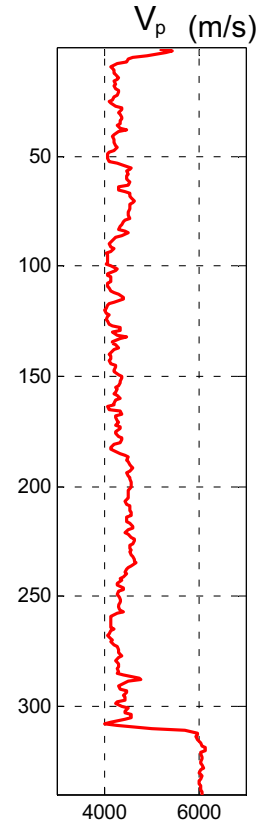

(a)

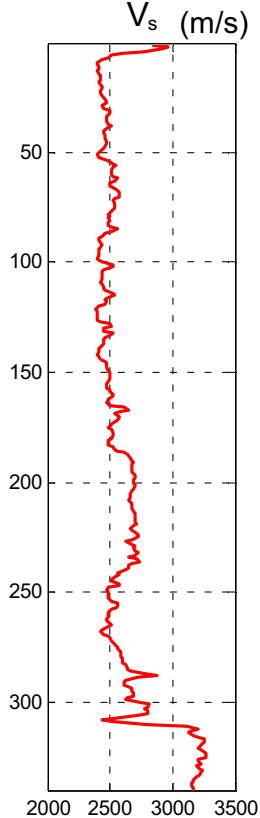

(b)

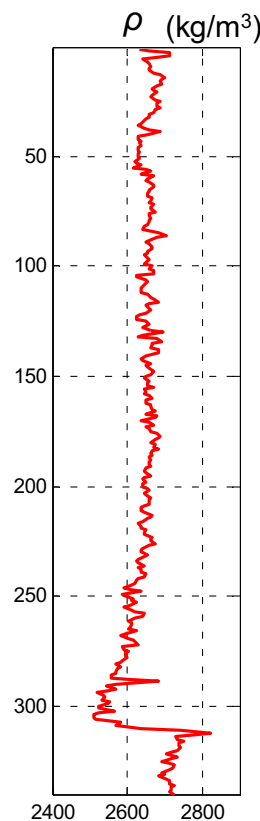

(c)

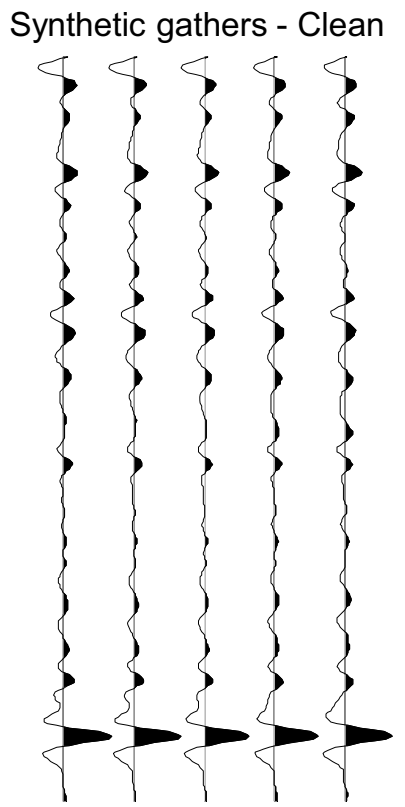

(d)

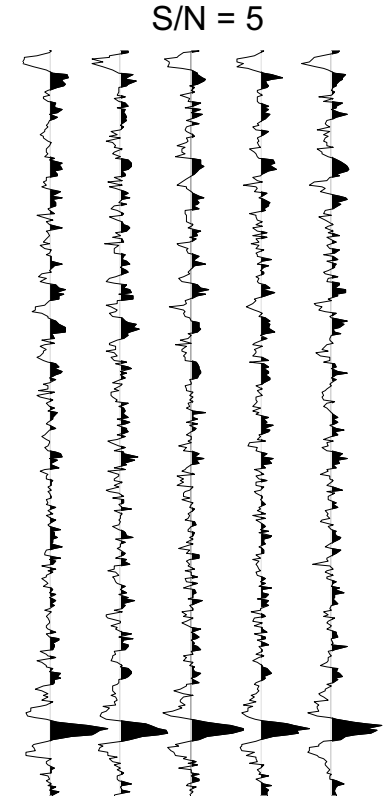

(e)

Fig. 9 Model parameters (a P-velocity; b S-velocity; c density) extracted from well JY8, as well as the synthetic clean (d) and noisy (e, S/N = 5) gathers. A Ricker wavelet with a dominant frequency of $25 \mathrm{~Hz}$ was used for modeling, and random noise was added to form noisy data

$R_{\mathrm{p}}=\frac{1}{2}\left(\frac{\Delta \rho}{\rho}+\frac{\Delta V_{\mathrm{p}}}{V_{\mathrm{p}}}\right), \quad R_{\mathrm{s}}=\frac{1}{2}\left(\frac{\Delta \rho}{\rho}+\frac{\Delta V_{\mathrm{s}}}{V_{\mathrm{s}}}\right)$ and $V_{\mathrm{p}}, V_{\mathrm{s}}$ and $\rho$ are the average P-wave velocity, S-wave velocity and density of the reflection boundary, 

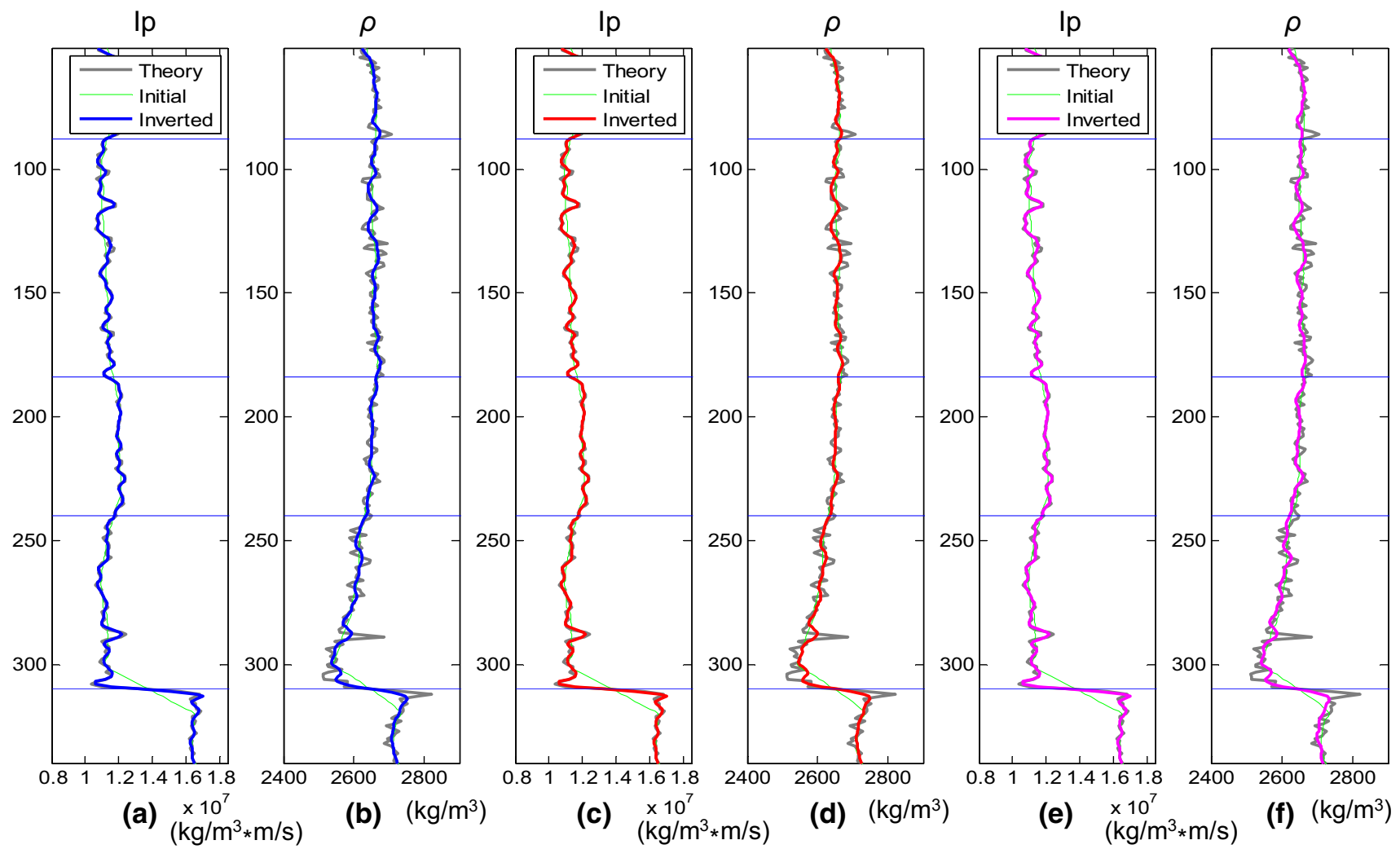

Fig. 10 Comparison between the P-impedance (Ip) and density ( $\rho$ ) inversion results from the non-regularized (a, b), traditional (c, d) and proposed $(\mathbf{e}, \mathbf{f})$ regularization inversion methods for data uncontaminated with noise

respectively. $\theta$ is the average of incidence and transmission angles. $R_{\mathrm{pp}}(\theta)$ is the elastic reflectivity with the ray path of incident angle, and $\Delta \rho / \rho$ is the density gradient. $V_{\mathrm{s}} / V_{\mathrm{p}}$ is the S-to-P-wave velocity ratio. If we use seismic amplitudes of CRP gathers to substitute $R_{\mathrm{pp}}(\theta)$, then the computed corresponding $R_{\mathrm{p}}$ results are the zero-offset P-wave reflection data. Compared to conventional full-stack data, the computed P-wave data have higher resolution and are more beneficial for reservoir prediction (Zhang et al. 2013) and pseudo-P-impedance inversion within the post-stack inversion framework.

\subsection{Regularized pre-stack inversion}

The pre-stack inversion is found to be efficient for extracting elastic parameters that are crucial for subsurface reservoir or fluid prediction (Connolly 1999; Hampson et al. 2005; Shamsa and Lines 2010; Yin et al. 2015). However, the actual pre-stack inversion problems for seismic exploration are ill-posed, and the objective function simply based on the least square error between synthetics and seismograms is difficult to be steadily and rationally solved. To gain more stability and reduce nonuniqueness, numerous regularizations are usually implemented during inversion either explicitly or implicitly, for instance, the Bayesian approach of Buland and More (2003) which strongly depends on the choice of a prior probability distribution for the parameters of interest. The Ip $-\rho$ relation, i.e., Gardner equation, is often employed to form a density constraint during pre-stack inversion, since P-impedance is comparably more stable (Zhang et al. 2015). Instead, we use the $\mathrm{PIp}-\rho$ relation to formulate density in this paper.

\section{Results}

\subsection{Numerical data testing}

The well model constructed from well JY8 (Fig. 9a-c) is utilized for the validation of the proposed inversion method. We also test no regularization and traditional regularization based on the Ip $-\rho$ relation against the proposed regularization based on the $\mathrm{PIp}-\rho$ relation methods. Synthetic traces (Fig. 9d) are generated with the exact Zoeppritz equation. A Ricker wavelet with a dominant frequency of $25 \mathrm{~Hz}$ was used for modeling, and random noise was added to form noisy data (Fig. 9e). Under the condition that the modeled data have the minimum least square error with the input data, the non-regularized 

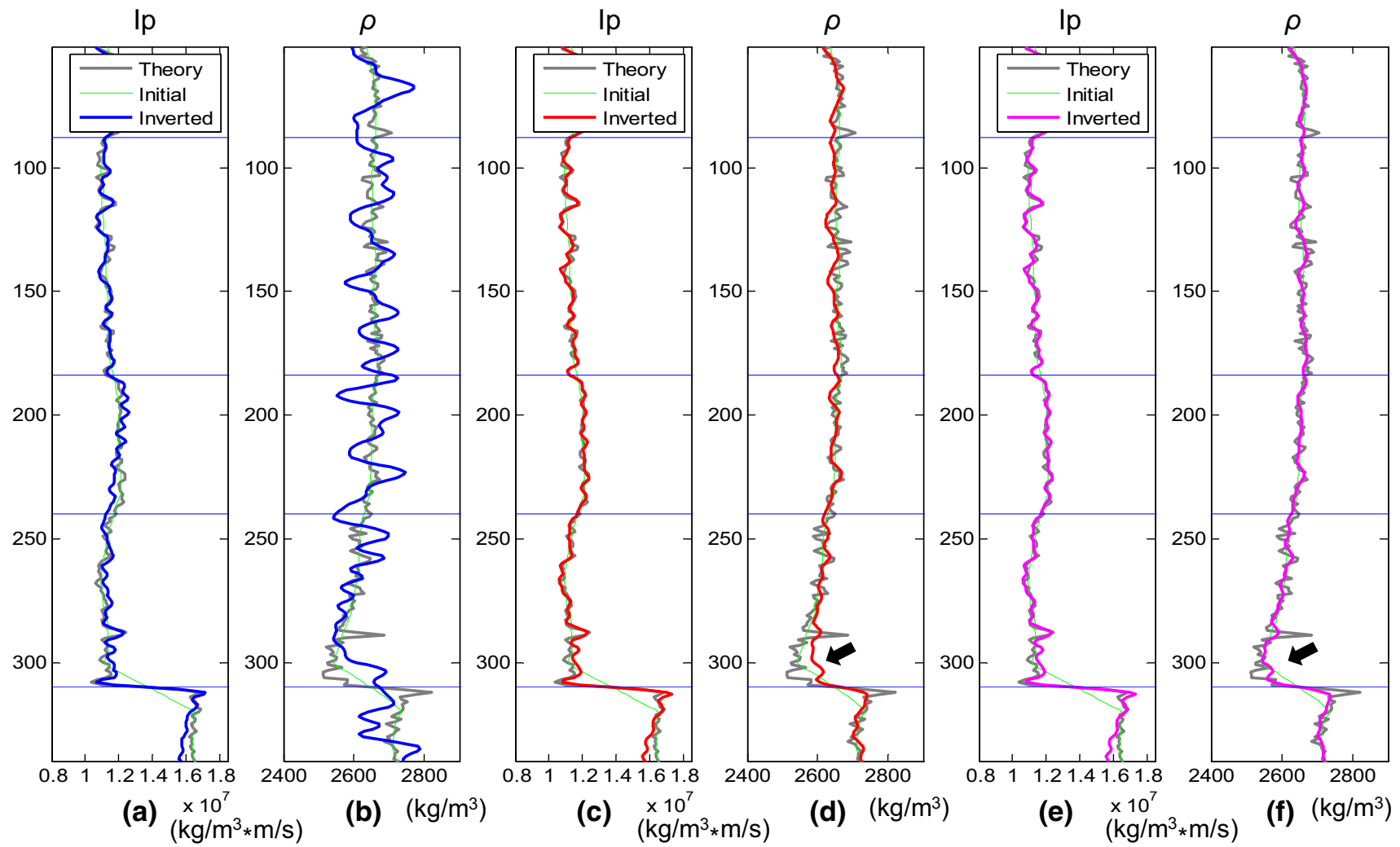

Fig. 11 Comparison between the P-impedance (Ip) and density $(\rho)$ from the non-regularized (a, b), traditional (c, d) and proposed (e, f) regularization inversion methods for noisy data with a signal-to-noise ratio of 5 . The good shale area is marked by the dark arrowhead

inversion primarily searches the results based on the objective function which only solves the minimum least square error between synthetics and seismograms. The second inversion method that is used in this paper is that of Zhang et al. (2015) which optimizes by adding Ip- $\rho$ (Fig. 6a) regularization, while the proposed method employs the PIp $-\rho$ relation (Fig. 6 b) to form new density constraints (Fig. 7d).

For clean data, high accuracy or resolution with subtle variations is achieved for the three P-impedance results (Fig. 10a, c, e) even though they started from smooth models (the fine green lines), while all the density results display the correct trend but lack fine-scale definition (Fig. 10b, d, f). Overall, all of the three methods are capable of obtaining similar and acceptable results. For noisy data (signal-to-noise ratio of 5), the non-regularized density inversion that lacks any prior information rapidly becomes incorrect. The presence of noise produces more severe perturbations for the density result (Fig. 11b) compared with that for P-impedance (Fig. 11a). This can be attributed to the fact that the density has a poorer solvability (Zhang et al. 2013). Unavoidably, this method will lead to an inappropriate characterization for the shale reservoirs in most cases. With the employment of necessary prior information, the inversion technique is implemented under a variety of regularizations to obtain a stable solution. We observe a significant stability for the two sets of regularized results (Fig. 11c-f). These P-impedance results (Fig. 11c, e) are close to the results without noise, except for some minor deviations (from the 280th to the 320th samples) near the lithology interface. The similarity between the P-impedance results (Fig. 11c, e) is derived from the use of the same input and constraints. However, the Ip $-\rho$ relation that is utilized in the traditional regularization guides density to be similar to P-impedance during the inversion process. For the sweetest shale reservoir that is rich in organic matter and renders a clear density decrease, the relatively weak P-impedance deflection is inferior as a guide for the density distribution (from the 280th to the 320th samples, marked by the dark arrowhead in Fig. 11d). In comparison, pseudo-P-impedance (PIp) that is reshaped by combining the acoustic and radioactivity properties possesses a better correlation with density, and the corresponding constraints have made a significant contribution to enhance density precision. The updated density result appears to be more accurate, especially for the good shale area (marked by the dark arrowhead in Fig. 11f). 

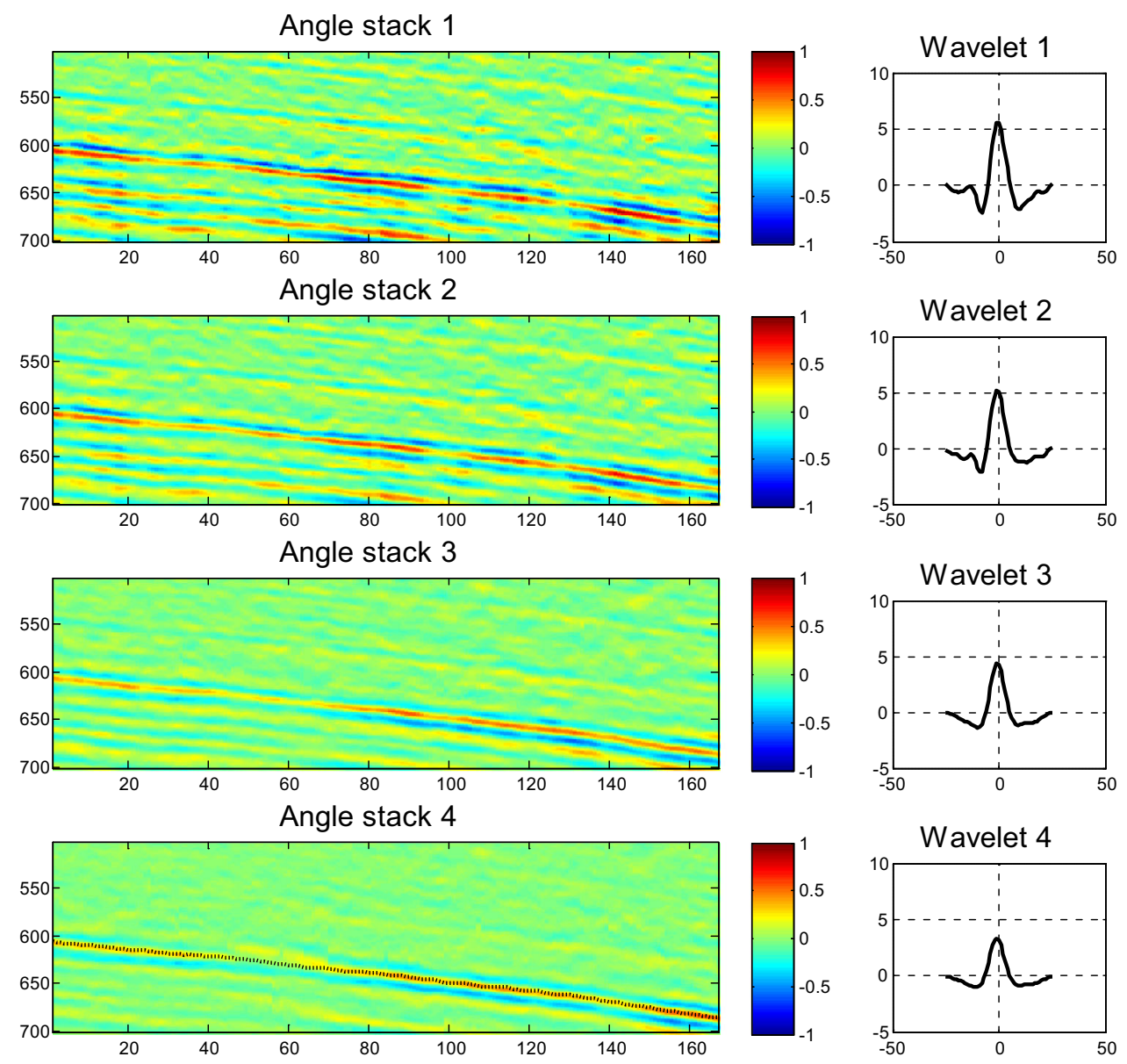

Fig. 12 Four angle stacks of the field data and corresponding estimated. The dashed black line on angle stack 4 indicates the boundary between the shale and the limestone

\subsection{Field data application}

The pre-stack time migrated data in the Jiaoshiba area are chosen for further analysis. The accuracy of inversion for any reservoir principally relies upon the quality of input data. Successful data processing in this area focuses on preserving the true amplitudes in the whole processing workflow, for example, amplitude compensation, noise attenuation, resolution enhancement and pre-stack migration (Chen et al. 2016). The key criterion for preserving amplitude is that the AVO characteristics between synthetic and data gathers should be similar. Using previous work from angle scanning and inversion testing (Su et al. 2016), four angle stacks $\left(3^{\circ}-9^{\circ}, 9^{\circ}-12^{\circ}, 12^{\circ}-18^{\circ}\right.$ and $18^{\circ}-$ $30^{\circ}$ ) are chosen for AVO inversion in this area. Wavelets are estimated based on the principle that their convolutions with reflectivity series form a best match with seismic traces. The input data are close to zero phase and gradually decrease in energy from the near to far stacks (Fig. 12). The large velocity variation from the shale to carbonate has created an obvious peak on the seismic section, which can be clearly observed and tracked on the stacked data (marked by the dashed line in angle stack 4).

Based on accurate horizon calibration and structural interpretation, it is a key procedure to build a low-frequency model for pre-stack inversion because it can greatly influence the inversion result. The structure in this area is simple, and it is easy to build a structural framework. Integrated with logging data and the geology framework, low-frequency models are built to include the P-impedance (Ip), S-impedance (Is) and density $(\rho)$ models. We conducted the three previous inversion tests for each type of regularization. Further, the pseudo-P-impedance (PIp) model is constructed to aid and constrain the density solution as described previously.

Figures 13 and 14 show a typical line across the shale reservoir in the Jiaoshiba area. The structure plunges from the left toward the right, with a slight slope. The marine shales of the Ordovician Wufeng Formation to the Silurian Longmaxi Formation in this area are deposited above a tight carbonate and always produce a detectable interface (dashed line in Figs. 12, 13, 14). The shale exploration 
(a) Ip: non-regularization

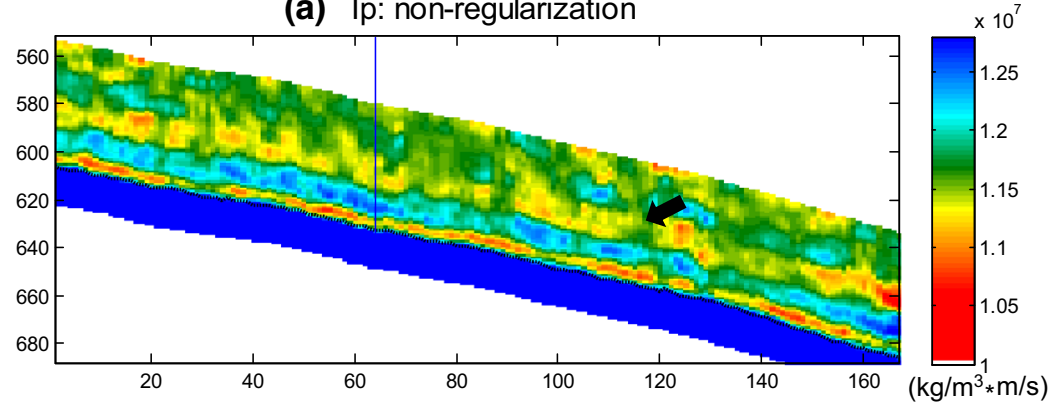

(b) Ip: traditional regularization

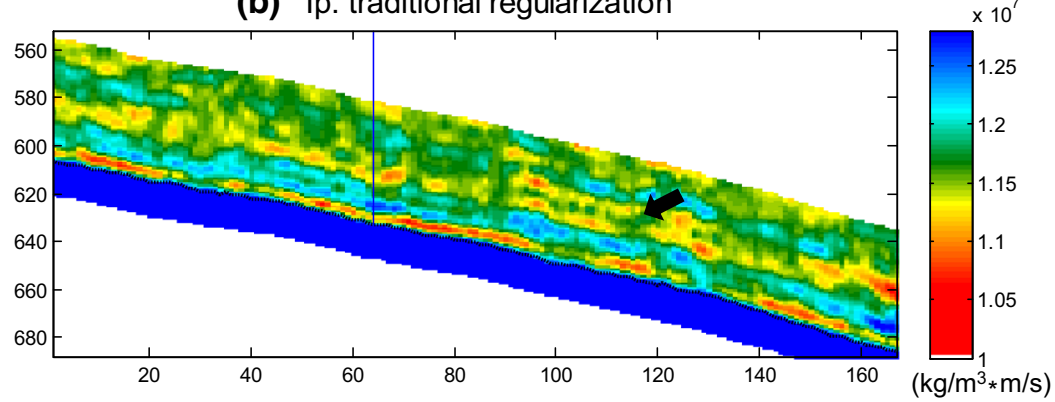

(c) Ip: proposed regularization

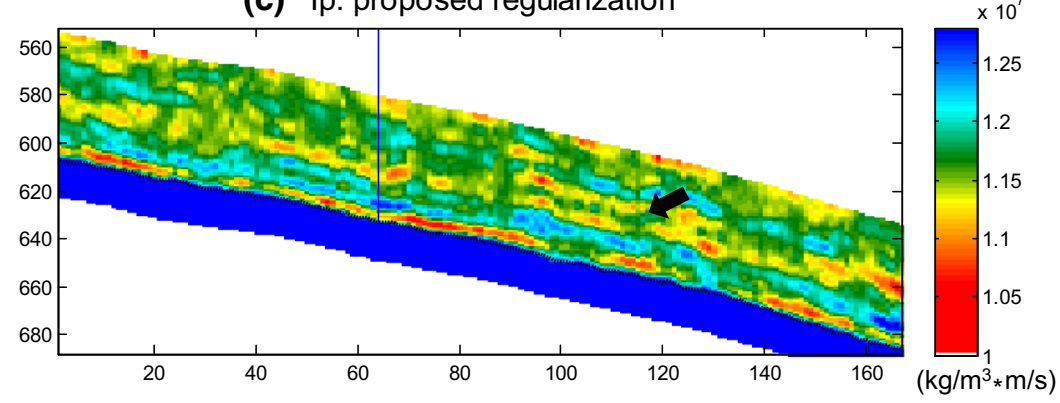

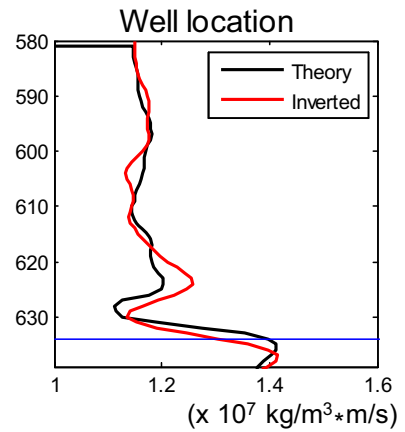
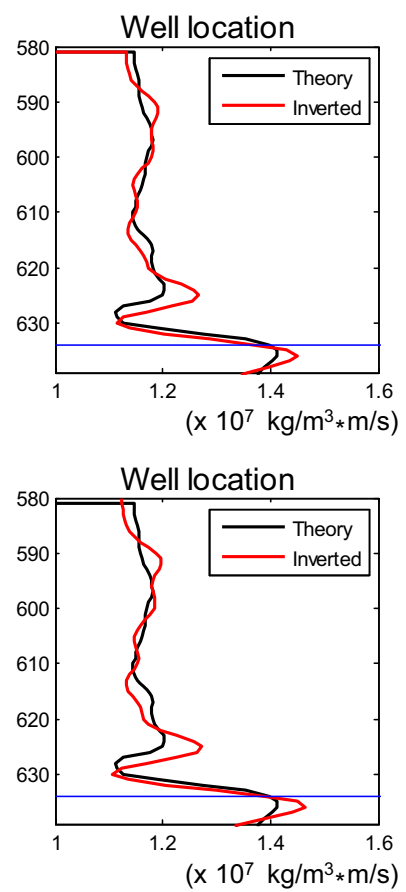

Fig. 13 Comparison of three inverted P-impedance results based on the non-regularization (a), traditional (b) and proposed (c) regularizations. Red and yellow areas in these figures indicate good quality shale reservoirs. The three inverted P-impedance results at the well

intervals with total thicknesses ranging from 90 to $250 \mathrm{~m}$ are producing gas. During the early Silurian, the depositional environment changed from deepwater continental shelf to shallow-water continental shelf, and these shales gave a good quality reservoir that is rich in organic matter and graptolite fossils with an average thickness of $38 \mathrm{~m}$. The subsequent shale depositions (with an average thickness of $170 \mathrm{~m}$ ) are composed of gray mudstone and argillaceous siltstone with a generally inferior quality (He et al. 2015; Yang and He 2015).

Generally, shale reservoirs are characterized as having lower P-impedance and density values compared with those of the underlying limestone. As shown in Fig. 13, all the three listed inversion methods present relatively stable P-impedance (Ip) results, displaying a generally similar sedimentary pattern including the overlying shale location (blue line in a-c, sample 580-641) were, respectively, extracted and compared with logging data at the seismic band on the right. The resolution difference between three inverted results is marked by the dark arrowheads

(lower Ip values, from the green to red color) and underlying limestone (steady large values, blue color). Due to the focus on obtaining high data quality, the P-impedance that is calculated from the non-regularized inversion also adequately reflects the general sedimentation, albeit with a slightly inferior resolution compared to the regularized results (marked by the dark arrowheads). However, the non-regularized method is obviously incapable of coping with this level of noise and provides a poor density result (Fig. 14a). This density result shows severe distortions in both lateral and vertical directions, with an unreasonable density range $\left(2380-2850 \mathrm{~kg} / \mathrm{m}^{3}\right)$ that is larger than its counterparts $\left(2560-2700 \mathrm{~kg} / \mathrm{m}^{3}\right)$ in Fig. $14 \mathrm{~b}$, c. This method will lead to an inaccurate shale characterization for this case. 
(a) $\rho$ : non-regularization

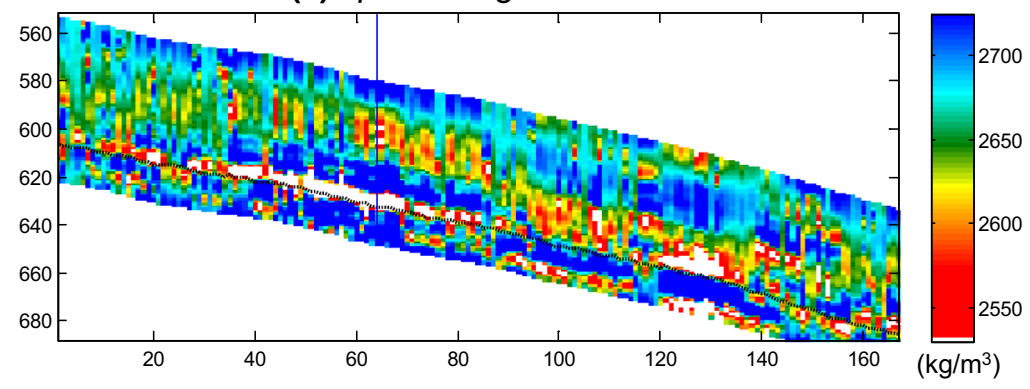

(b) $\rho$ : traditional regularization

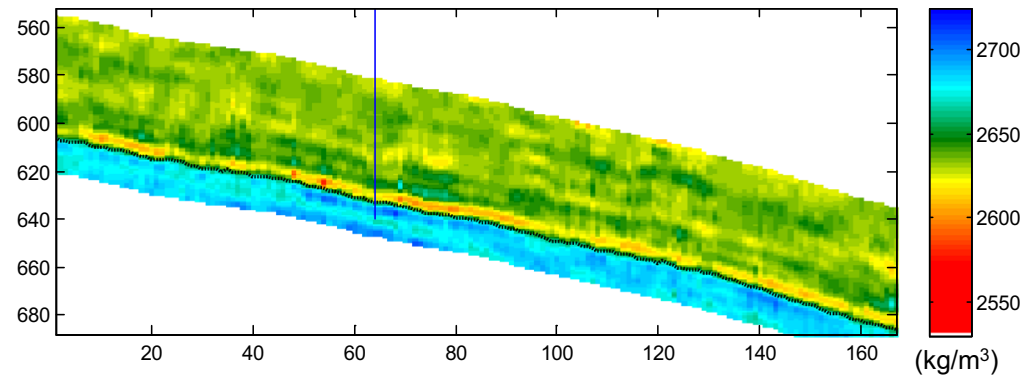

(c) $\rho$ : proposed regularization

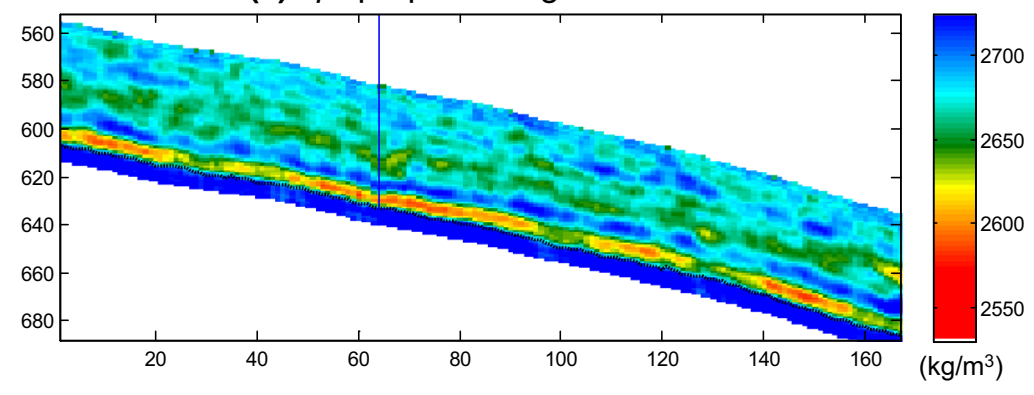

Well location

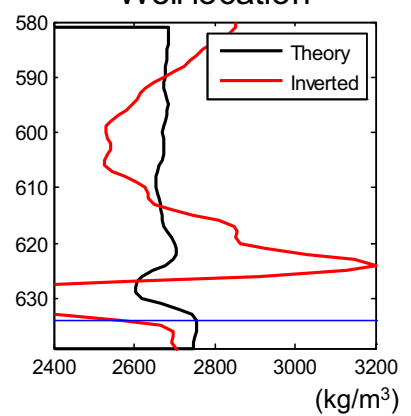

Well location
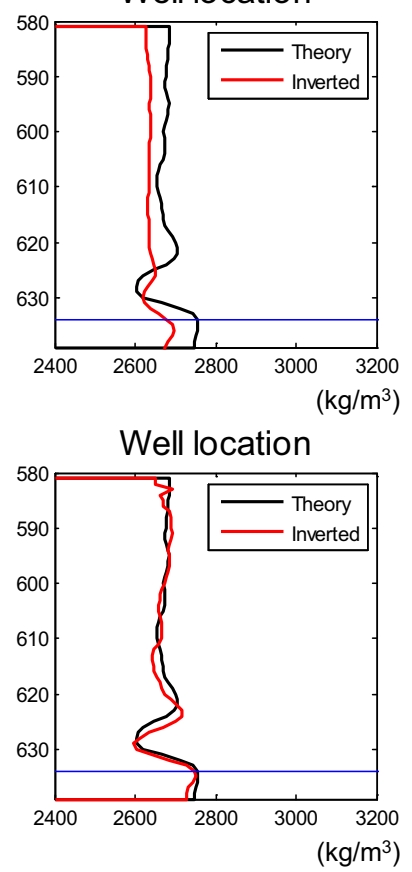

Fig. 14 Comparison of three inverted density results based on the non-regularization (a), traditional (b) and $\mathbf{c}$ proposed regularizations. Red and yellow areas in these figures indicate good quality shale

We observed that the methods that are under the constraints of prior information can significantly improve the stability of the inversion (Figs. 13b, c, 14b, c). For density that is inverted by using traditional regularization methods (Fig. 14b), the resultant pattern is quite similar to that of Ip (Fig. 13b) due to constraints from the Ip- $\rho$ relation. Although it has successfully achieved the desired resolution, the whole shale layer above the carbonate sediments is inaccurately assessed as a similar quality. In comparison, the sweetest shale reservoirs during the early Silurian are fairly well determined (red and yellow color in Fig. 14c), by utilizing the constraints of the PIp- $\rho$ relation. The overlying shales are demarcated by an inadequate deflection on the density result, revealing an inferior shale formation marked by the ellipse in Fig. 14c. Overall, the general scenario suggested from Fig. $14 \mathrm{c}$ is more consistent with the exploration results and is validated by well reservoirs. The three inverted density results at the well location (blue line in a-c, sample 580-641) were, respectively, extracted and compared with logging data at the seismic band on the right

parameters, where the early shale deposition is richer in the organic matter and graptolite fossils, while the subsequent deposition is composed of gray mudstone and argillaceous siltstone with a generally inferior quality rock (He et al. 2015; Yang and He 2015).

\section{Conclusions}

For ill-posed pre-stack inversion in the field area, especially for those unconventional reservoirs that require precise density determination, appropriate prior information is absolutely necessary to guide the optimization of the inversion process. A non-regularized AVO inversion tends to provide a noisy and distorted density result, while utilizing improper constraints will also generate an incorrect estimation of the reservoir distribution. For the shale gas 
reservoir in the Jiaoshiba area, we found the P-impedance can be efficiently solved by the pre-stack seismic inversion, albeit the non-regularized result has a slightly inferior resolution compared to the regularized results. Nevertheless, the non-regularized method provided a poor density result with severe distortions in both lateral and vertical directions. Although the traditional regularization based on the Ip- $\rho$ relation successfully achieved the desired resolution, the whole shale layer above the carbonate sediments is inaccurately assessed as a similar quality. However, the proposed method based on the PIp- $\rho$ relation is capable of highlighting the organic-rich shale interval from the generally inferior quality rocks.

Acknowledgements The authors thank the NSFC and Sinopec Joint Key Project (U1663207), the China Geology Survey Project (DD20160195), 973 Program (2014CB239104), National Key S\&T Projects (2017ZX05049002) and China Postdoctoral Science Foundation for the financial support. We appreciate Exploration and Development Research Institution in the Jianghan Oilfield for providing the data.

Open Access This article is distributed under the terms of the Creative Commons Attribution 4.0 International License (http://creative commons.org/licenses/by/4.0/), which permits unrestricted use, distribution, and reproduction in any medium, provided you give appropriate credit to the original author(s) and the source, provide a link to the Creative Commons license, and indicate if changes were made.

\section{References}

Alemie W, Sacchi MD. High-resolution three-term AVO inversion by means of a Trivariate Cauchy probability distribution. Geophysics. 2011;76(3):25-34. https://doi.org/10.1190/1.3554627.

Behura J, Kabir N, Crider R, et al. Density extraction from P-wave AVO inversion: Tuscaloosa Trend example. Lead Edge. 2010;29(7):772-7. https://doi.org/10.1190/1.3462777.

Buland A, More H. Bayesian linearized AVO inversion. Geophysics. 2003;68(1):185-98. https://doi.org/10.1190/1.1543206.

Chen J, Yin X. Three-parameter AVO waveform inversion based on Bayesian theorem. Chin J Geophys. 2007;50(4):1251-60. https:// doi.org/10.3321/j.issn:0001-5733.2007.04.035 (in Chinese).

Chen L, Lu YC, Jiang S, et al. Heterogeneity of lower Silurian Longmaxi marine shale in the southeast Sichuan Basin of China. Mar Pet Geol. 2015a;65:232-46. https://doi.org/10.1016/j.mar petgeo.2015.04.003.

Chen L, Lu YC, Jiang S, et al. Sequence stratigraphy and its application in marine shale gas exploration: a case study of the Lower Silurian Longmaxi Formation in the Jiaoshiba shale gas field and its adjacent area in southeast Sichuan Basin, SW China. J Nat Gas Sci Eng. 2015b;27:410-23. https://doi.org/10.1016/j. jngse.2015.09.016.

Chen ZQ, Yang HF, Wang JB, et al. Application of high-precision 3D seismic technology to shale gas exploration: a case study of large Jiaoshiba shale gas field in the Sichuan Basin. Nat Gas Ind. 2016;3:117-28. https://doi.org/10.1016/j.ngib.2016.03.006.

Connolly P. Elastic impedance. Lead Edge. 1999;18:438-52. https:// doi.org/10.1190/1.1438307.
Debski W, Tarantola A. Information on elastic parameters obtained from the amplitudes of reflected waves. Geophysics. 1995;60(5):1426-36. https://doi.org/10.1190/1.1443877.

Downton JE. Seismic parameter estimation from AVO inversion. Ph.D. Thesis, University of Calgary. 2005.

Downton J, Lines L. Three term AVO waveform inversion. In: 74th SEG annual meeting, expanded abstracts. 2004. https://doi.org/ 10.1190/1.1851205.

Downton J, Lines L. et al. Constrained three parameter AVO inversion and uncertainty analysis. In: 71st SEG annual meeting, expanded abstracts. 2001. https://doi.org/10.1190/1.1816583.

Gidlow PM, Smith GC, Vail PJ. Hydrocarbon detection using fluid factor traces: a case history. In: Expanded abstracts of the joint SEG/EAEG summer research workshop on "How useful is amplitude-versus-offset (AVO) analysis?” p. 78-89. 1992.

Gray D. P-S converted-wave AVO. In: 73rd SEG annual meeting, expanded abstracts. 2003. https://doi.org/10.1190/1.1817623.

Hampson DP, Russell BH, Bankhead B. Simultaneous inversion of pre-stack seismic data. In: 75th SEG expanded abstract, p. 1633-7. 2005. https://doi.org/10.1190/1.2148008.

Hao F, Guo TL, Zhu YM. Evidence for multiple stages of oil cracking and thermo-chemical sulfate reduction in the Puguang gas field, Sichuan basin, China. AAPG Bull. 2008;92(5):611-37. https:// doi.org/10.1306/01210807090.

$\mathrm{He}$ C, He S, Peng N. Organic pore structures and origin in the Lower Paleozoic marine shales of Jiaoshiba Region of Sichuan Basin, China. In: AAPG international conference and exhibition, Melbourne, 12-16 Sept 2015, p. 331. https://doi.org/10.1190/ ice2015-2210709.

Jeony W, Min DJ. Application of acoustic full waveform inversion for density inversion. In: 82nd SEG annual meeting, expanded abstracts. 2012. https://doi.org/10.1190/segam2012-0196.1.

Jiang S, Tang XL, Long SX, et al. Reservoir quality, gas accumulation and completion quality assessment of Silurian Longmaxi marine shale gas play in the Sichuan Basin, China. J Nat Gas Sci Eng. 2017;39:203-15. https://doi.org/10.1016/j.jngse.2016.08. 079 .

Liang C, Jiang ZX, Yang YT, et al. Shale lithofacies and reservoir space of the Wufeng-Longmaxi Formation, Sichuan Basin, China. Pet Explor Dev. 2012;39:736-43. https://doi.org/10.1016/ S1876-3804(12)60098-6.

Liang C, Jiang ZX, Cao YC, et al. Deep-water depositional mechanisms and significance for unconventional hydrocarbon exploration: a case study from the lower Silurian Longmaxi shale in the southeastern Sichuan Basin. AAPG Bull. 2016;100(5):773-94. https://doi.org/10.1306/02031615002.

Liu L, Sun Z, Luo C, et al. A noise-resisitant density inversion algorithm and its application on high efficiency well selection for complex carbonate reservoir. In: 83rd SEG annual meeting, expanded abstracts. 2013. https://doi.org/10.1190/segam20131216.1.

Russell BH, Hampson D. Simultaneous inversion of pre-stack seismic data. In: 77th SEG annual meeting, expanded abstracts. 2007. https://doi.org/10.1190/1.2148008.

Shamsa A, Lines L. A case study in the application of inversion methods to a Persian Gulf reservoir. In: 80th SEG expanded abstract, p. 2896-900. 2010. https://doi.org/10.1190/1.3513447.

$\mathrm{Su} \mathrm{J}, \mathrm{Qu} \mathrm{D}$, Chen C, et al. Application of pre-stack inversion technique for shale gas in Jiaoshiba gas field. Oil Geophys Prospect. 2016;51(3):581-8. https://doi.org/10.13810/j.cnki.issn. 1000-7210.2016.03.021 (in Chinese).

Sun, Z. Seismic methods for heavy oil reservoir monitoring and characterization. Ph.D. thesis, University of Calgary. 1999.

Theune U, Jensas I, Eidsvik J. Analysis of prior models for a blocky inversion of seismic AVA data. Geophysics. 2010;75(3):C25-35. https://doi.org/10.1190/1.3427538. 
Yan W, Wang JB, Liu S, et al. Logging identification of the Longmaxi mud shale reservoir in the Jiaoshiba area, Sichuan Basin. Nat Gas Ind. 2014;1:230-6. https://doi.org/10.1016/j. ngib.2014.11.016.

Yang R, He S. Geochemical characterization and shale gas potential of the Longmaxi shale formation of Lower Silurian in Jiaoshiba area, southeast Sichuan Basin, China. In: AAPG international conference and exhibition, Melbourne, 12-16 September 2015, p. 331. https://doi.org/10.1190/ice2015-2205136.

Yin J, Wang X, Yang R, Xie Z, Liu Z. Application of pseudo sonic $\log$ recomposition technique based on multiple well logs. Xinjiang Pet Geol. 2014a;35(4):461-5 (in Chinese).

Yin Z, Chen C, Peng C. Application of pseudo-acoustic impedance inversion to quality shale reservoir prediction: a case study of the Jiaoshiba shale gas field, Sichuan Basin. Nat Gas Ind. 2014b;34(12):33-7.

Yin $\mathrm{XY}$, Liu XJ, Zong ZY, et al. Pre-stack basis pursuit seismic inversion for brittleness of shale. Pet Sci. 2015;12(4):618-27. https://doi.org/10.1007/s12182-015-0056-3.
Zhang YY, Sun ZD, Yang HJ, et al. Pre-stack inversion for caved carbonate reservoir prediction: a case study from Tarim Basin, China. Pet Sci. 2011;8(4):415-21. https://doi.org/10.1007/ s12182-011-0159-4.

Zhang JH, Zhang YY, Sun ZD, et al. The effects of seismic data conditioning on pre-stack AVO/AVA simultaneous inversion. Oil Geophys Prospect. 2012;47(1):68-73. https://doi.org/10. 13810/j.cnki.issn.1000-7210.2012.01.017 (in Chinese).

Zhang YY, Sun ZD, Fan CY. An iterative AVO inversion workflow for S-wave improvement. In: 75th EAGE annual meeting, expanded abstracts. 2013. https://doi.org/10.3997/2214-4609. 20130268.

Zhang YY, Sun ZD, Fan CY. A pre-stack three-term AVO inversion method based on integrated norm regularization. In: 77th EAGE annual meeting, expanded abstracts. 2015. https://doi.org/10. 3997/2214-4609.201412627. 